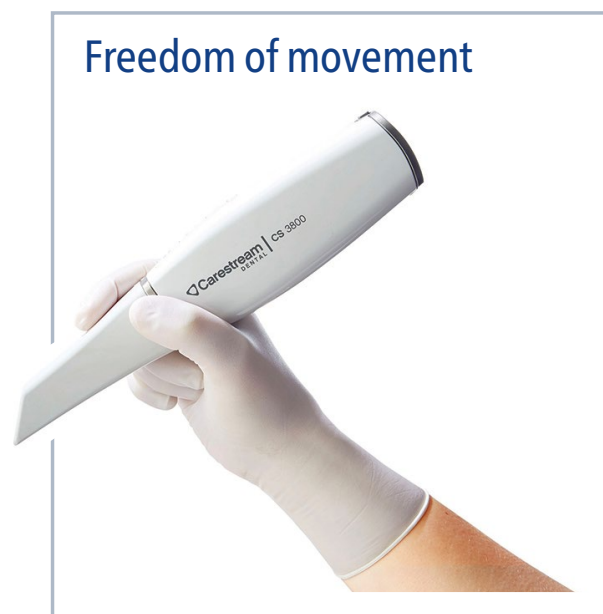

When it comes to intraoral scanning, you need a solution that offers versatility and freedom. So why not revolutionise the way you scan with the new CS 3800 intraoral scanner from Carestream Dental?

Featuring state-of-the-art wireless technology, the scanner allows for ultimate mobility and freedom of movement during image acquisition. Plus, with ultra-fast scans, enhanced reporting features and a host of other benefits, you can enter a new generation of scanning with ease.

For more information, contact Carestream Dental on 08001699692 or visit www.carestreamdental.co.uk.

\section{Legal assistance for all your needs}

Working solely with dentists, lawyers4dentists is a legal firm that understands the ins and outs of the industry. All of their specialist dental experts have decades of experience and are on hand to provide you with painless, polished legal services to guide you through any legal queries you may have.

lawyers4dentists works closely with all of its sister companies in the 4 dentists group, meaning that you can always rely on expert advice that truly takes into account every unique element of the dental industry.

To find out more, contact the team today.

For more information call 0845 3455060 or 0754 DENTIST. Email info@4dentistsgroup.com or visit www.4dentistsgroup.com.

\section{The first truly Al dental software of its kind}

TapNote promises to save dentists time, improve patient safety, and prevent litigation, all using an evolving artificial neural network calibrated by leading clinical minds.

Co-owners Dr Connor Bryant and Dr Priyam Patel founded Aura AI as a division of Bryant Medical, a health-tech powerhouse which delivers next-generation medical equipment to dentists around the world.

As clinicians themselves, they fully understand the issues which dentists face on a day-to-day basis and aim to use the cutting edge of technology to enable every dentist to achieve excellence.

TapNote was created to solve the issue of litigation in dentistry, an issue which was reported to cause anxiety and stress in $90 \%$ of UK dentists. ${ }^{1}$ The unique neural network allows the software to predict personalised risk profiles and diagnoses, as well as generate comprehensive notes quickly and reliably, ensuring that informed consent is obtained every time. This not only reduces the burden of litigation, but improves patient safety and brings dentistry into a new era.

The first truly AI dental software of its kind, TapNote's neural network learns and improves with every user and enables the generation of personalised predictive health

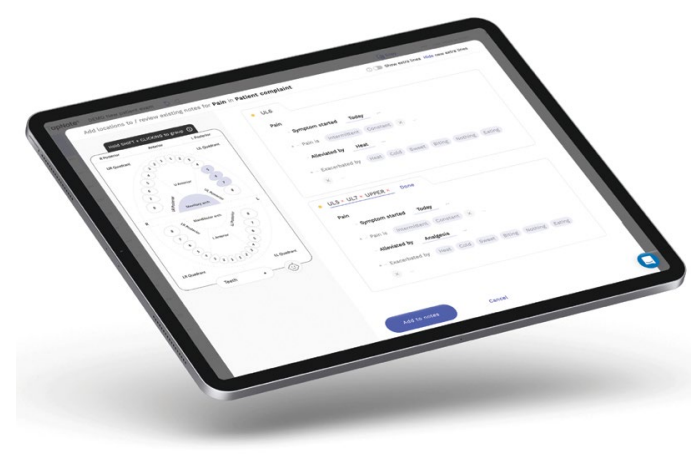

records. Moreover, due to sophisticated machine-learning algorithms, the accuracy of TapNote's suggestions only improves with increased numbers of users.

Part of a much larger practice management software, TapNote is the first part of AURA, an all-encompassing AI practice manager which includes functionality for intelligent stock tracking, diary optimisation and instant auditing, on track for release in 2022.

https://bryant.dental/aura

\section{Reference}

1. Dental Protection. Dental Protection survey reveals 9 in 10 dentists fear being sued by patients. 17 October 2018. Available at: https://www.dentalprotection. org/uk/articles/dental-protection-survey-reveals-9in-10-dentists-fear-being-sued-by-patients (accessed October 2021).

\section{Multi-use self-adhesive cement}

SoloCem, the self-adhesive cement from COLTENE, is now multi-use. You can use it on its own, or boost it with ONE COAT 7 UNIVERSAL, for the new SUPERKRAFT! That's two products that are strong individually; together, unbeatable.

The obvious benefits are that you can:

- Reduce stock

- Gain time with patients

- Achieve reliable bond strength on enamel and dentine.

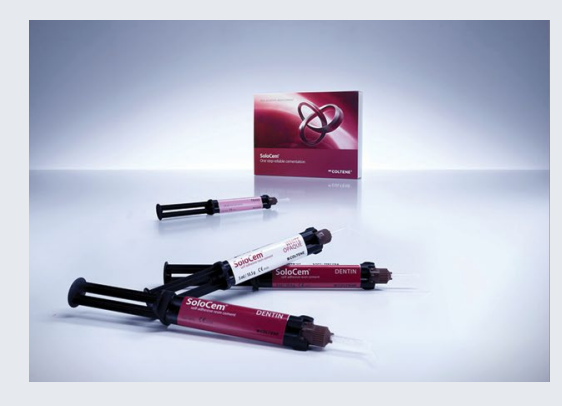

Simple, stripped-down dentistry is quality dentistry, upgraded to maximise efficiency with no compromise to clinical outcomes.

Your work will be safe, stable and successful - one-step cementation from SoloCem, with ONE COAT 7 UNIVERSAL as an adhesion booster.

Contact COLTENE today, to accomplish more with SUPERKRAFT.

For more on COLTENE, visit www. coltene.com, emailinfo.uk@coltene.com or call 08002545115 .

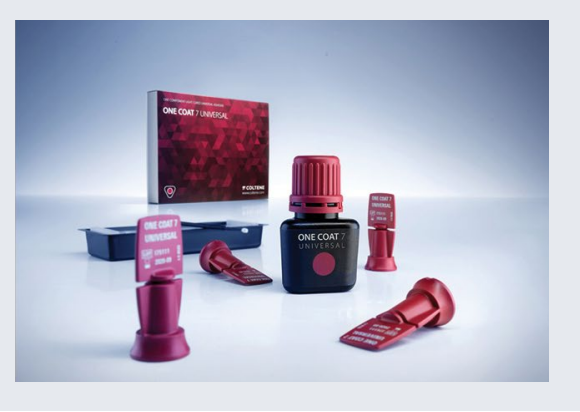

